\title{
Psychotherapists Working in Private Practice During a Pandemic: A Literature Review
}

\author{
Christine L. Duquette \\ Touro University Worldwide \\ Stephanie M. Morgan \\ Touro University Worldwide
}

\section{ABSTRACT}

Psychotherapists in private practice provide services to an ever-growing client population. The 2020 novel Corona Virus (COVID-19) pandemic was a catalyst for emerging and exasperated mental health concerns among the U.S. population. The result was an increase in demand for services and private practitioners stepping up to meet this growing need. Little is known about the psychotherapists who embark on independent practice and less is known about the nuances of practicing during a global pandemic. The aim of this review was to exhaust the literature on private practice psychotherapy and the practice of psychotherapy during COVID-19, synthesize the findings, report on themes in the literature, and provide recommendations for future lines of inquiry. Themes from this review included the impact of COVID-19 on public mental health, telemental health, private practice shifts, and private practice careers.

Keywords: psychotherapists, private practice, COVID-19, telemental health, pandemic psychotherapy

\section{Psychotherapists Working in Private Practice During a Pandemic: A Literature Review}

Psychotherapists are employed in a variety of treatment settings and among the top is a private practice office. Unfortunately, little is known about those psychotherapists who embark on practicing independently, in a private practice setting. The personal, professional, and contextual variables that influence the decision to work independently in private practice have not been adequately explored. Research historically centers on the patient, not the practitioner and the modality, nor the course of professional development. While the study of patients, their presenting problems, and the search for effective treatments are critical to evidence-based practice, the practitioner and professional identity are important variables to consider.
Many therapists dramatically changed the way they deliver services, and some opted to transition to private practice following the onset of the 2020 novel Corona Virus (COVID19) pandemic (Polovoy \& Kornak, 2020). The reach of COVID-19 extended to all facets of life, and people had to pivot in order to accommodate widespread global change. On March 17th, 2020, the Centers for Medicare and Medicaid expanded and relaxed previous telehealth rules allowing for full telehealth services and reducing or eliminating patient cost-sharing in the form of deductibles and copays (Inserro, 2020). Other private insurance providers followed suit initiating similar changes (America's Health Insurance Providers [AHIP], 2021). Taken together, these changes had significant implications for mental health services, including who needed services, how services were delivered, where services were 
delivered, and how service providers were mobilized to meet the needs of a growing client population. Psychotherapists who followed the previously standard model of in-office and inperson visits (i.e., offices, health care facilities, treatment centers, and myriad other mental health settings) shifted to providing telehealth, often from their homes (Aafjes-van Doorn et al., 2020). The pandemic proved to be a call for therapists to meet a growing need for services, and yet little is known about how therapists work in private practice and even less about how they prepare for change to support clients during global unrest and pandemics.

The dearth of research on practitioners may be influenced by the clinical truism that practitioners are or should be blank slates for their clients. The gaps in the literature include motivations for career choice, career sustainability, and how private practitioners specifically support clients during global crises. Additionally, it is difficult to conceptualize roles and constructs such as psychotherapist, private practice, and varying ways of practicing among innumerable licensure statuses. For the purpose of this review, the term psychotherapist refers to an independently licensed masters or doctoral level practitioner who provides psychotherapy to clientele. The terms practitioner, provider, psychotherapist, and therapist will be used interchangeably.

The aim of this review is to explore the current theoretical and practical understandings of psychotherapeutic private practice during a global pandemic, synthesize and report on the overarching themes, and provide recommendations for future research that may lead to a better understanding of the nuances of the role and impact of work done by providers in this setting, especially during times of rapid change and unprecedented crises. The following databases were utilized for this review: Proquest, Google Scholar, EbscoHost, and ERIC. In order to be included in this review, articles must have been written in English, peerreviewed or published from a direct source (eg. Insurer or licensing board) and published within the last ten years. The following key terms and phrases were used: psychotherapy/ists in private practice, psychotherapy during COVID, therapists in private practice, COVID and mental health, motivation for private practice, psychotherapy and pandemics, and COVID and psychotherapy changes.

\section{The Impact of COVID-19 on Public Mental Health}

COVID-19 brought on major disruptions in the lives of many individuals and is projected to result in long-term negative mental health outcomes across the globe (Boden et al., 2021; Lie et al., 20210). Measures taken to respond to the pandemic have considerably shifted everyday life including routines, occupational and academic obligations, and shared spaces in the home; the result has been a complex array of stressors with negative impacts on public mental health (Javakhishvili et al., 2020; Khan et al., 2020; Lewis et al., 2021). The pandemic created specific issues related to both mental health and the people who provide mental health services (Lu et al., 2020; Soklaridis et al., 2020). The outbreak of COVID-19 has resulted in a growing body of research around the psychological impact of infection, fear of infection, and quarantine. Itrat et al. (2020) asserted that quarantine has had a clear negative impact on public mental health. Lee (2020) noted that as school was often a conduit for children and adolescents in need of mental health services, COVID-19 and related school closures left many children and families abruptly without necessary services. Taylor et al. (2020) went so far as to coin the term COVID stress syndrome to describe five factors of COVIDrelated distress, including fear of getting COVID19 , socioeconomic worries, xenophobia related to fears of foreigners spreading the virus, symptoms of traumatic stress, and compulsive checking and hypervigilance.

The demands of responding to the virus itself may have diverted resources away from mental healthcare (Mauro et al., 2020; van der Miesen et al., 2020). As governments responded to the global threat, restrictions like travel bans, business and school shutdowns, strict social distancing, and stay-at-home orders led to an uptick in the experience of mental health symptoms (AJMC, 2021; Rothe et al., 2021). These restrictions, in turn, resulted in several added stressors for many individuals and families, including employment challenges, income loss, financial difficulties, isolation, 
greater tension between people sharing households, stress over the virus itself, and a barrage of conflicting information, all adding to an already weighty burden (Davulis et al., 2021). Javakhishvili et al. (2020) noted that among many of the COVID-19 related changes in life circumstances, cultural constructs ranked highly and included further stigmatization, discrimination and community fragmentation, and even the loss of culturally significant mourning rituals.

Stress, anxiety, depression, sleep disorders, fatigue, boredom, feelings of isolation, and anger are among the most reported mental health systems related to COVID-19 (Davulis et al., 2021; Javed et al., 2020). A July 2020 health tracking poll from the Kaiser Family Foundation found that many adults reported specific negative impacts on their mental health related to the coronavirus, including sleep issues (36\%), eating issues (32\%), and increases in alcohol consumption and/or substance use (12\%) (Panchal et al., 2021). Additionally, a National Health Interview Survey (NHIS) found that from January to June in 2019 , just $11 \%$ of adults reported symptoms of anxiety or depressive disorder, with that number rising to $41.1 \%$ in a January 2020 household survey conducted by the U.S. Census Bureau (Panchal et al., 2021). A cross-sectional study using data from the Centers for Disease Control and Prevention National Syndromic Surveillance Program examined nearly 190 million emergency department visits finding higher rates of visits associated with mental health conditions, suicide attempts, drug overdoses, and child abuse and neglect from mid-March through October 2020 than the same period in 2019 (Holland et al., 2021). The Federal Disaster Distress Helpline, run by the Substance Abuse and Mental Health Services Administration and the nonprofit Vibrant Emotional Health, received a surge in calls and texts, answering over 25,000 calls and texts in March of 2020, more than eight times the number of calls and texts from February 2020 (Hopkins \& Russell, 2020).

Discussions centering around inequity in access to and general availability of mental health services were already taking place prior to the onset of the pandemic. To this point, a Kaiser Family Foundation analysis of the Substance Abuse and Mental Health Services
Administration (SAMHSA) restricted online data analysis system (RDAS), the National Survey on Drug Use and Health (NSDUH), and the 2018 and 2019 Substance Abuse and Mental Health Data Archive showed that $6.2 \%$ of adults reported an unmet need for mental health services between 2018 and 2019 (Kaiser Family Foundation, n.d.). A 2016 report from the U.S. Department of Health and Human Services examined projections for the supply and demand of behavioral health practitioners utilizing an integrated microsimulation model and found that shortages were predicted for clinical, counseling, and school psychologists; marriage and family therapists; substance abuse and behavioral disorder counselors; psychiatrists; mental health and substance abuse social workers; mental health counselors; and school counselors; and that these predicted shortages exceeded 10,000 full-time employees in each of the various positions (U.S. Department of Health and Human Services, 2016). These simulations were conducted utilizing multiple models, one with a baseline assuming equilibrium with 2013 provider supply and a second scenario estimating current shortages and projected demand. Neither scenario accounted for a global pandemic and the demands that might put on both the demand for behavioral health services and the supply of practitioners (U.S. Department of Health and Human Services, 2016). Individuals who had previously experienced mental health problems reported worsening symptoms as pandemic stressors and other risk factors increased negative mental health outcomes, particularly among already vulnerable populations (Boden et al., 2021). Some populations were particularly vulnerable to COVID-19 including those with chronic illnesses and pre-existing medical conditions, the elderly, and frontline workers (Davulis et al., 2021). Patients who contracted COVID-19 reported feelings of regret, resentment, isolation, helplessness and new or worsening symptoms of depression and anxiety. Even in patients with no previous history of mental illness, COVID-19 was associated with an increase in the onset of the first presentation of psychiatric symptoms (Taquet et al., 2021; Tingbo, 2020). Other socially disadvantaged populations were considered at heightened risk for greater mental health effects including those with disparities in 
education, income, employment, occupation, age, immigration status, sexual orientation, cultural/racial background, sex, and gender (Gibson et al., 2021; Litam \& Hipolito-Delgado, 2021). Preliminary studies suggested that the COVID-19 pandemic is likely associated with rises in reports of stress and anxiety (Ahorsu et al., 2020; Pierce et al., 2021), symptoms of posttraumatic stress disorder (PTSD) (Tingbo, 2020), and increased substance use issues (Rehm et al., 2020). The impacts of quarantine on those individuals with pre-existing mental illness showed while the symptoms themselves were similar to pre-pandemic, they were much more severe (Itrat et al., 2020).

Notably, many individuals reported new symptoms and instances of mental health impairment, despite having no prior symptoms or treatment episodes (Holingue et al., 2020; Rothe et al., 2021). In light of this, there was a rapid and marked increase in requests to initiate mental health services. Mental health services, similar to most other medical services during COVID-19, were recommended to be provided remotely when possible, and so, the majority of outpatient providers shifted their practices online (Punia et al., 2020). Many of the traditional therapeutic or intervention models were not scalable to meet the increased demand for mental health services (Boden et al., 2021). Duan and Zhu (2020) noted that mental health responses in emergency conditions require flexibility to meet rapid change and manage any inherent constraints. More people were looking for services just as access to services narrowed with the abrupt shift away from in-person services.

\section{Telemental Health}

Etymologically speaking, the word pandemic is related to pandemonium (Szasz, 2020), and pandemonium accurately described the early days of psychotherapists transitioning their practices to telemental health. In the immediate aftermath of COVID-19 restrictions, there was tremendous confusion about how to follow state and federal mandates, stay safe, keep the public safe, deliver services, limit liability, assure insurance reimbursement of services, maintain the integrity of legal and ethical guidelines, and operate within the law, or at the very least, within the "spirit" of the law.
Clinicians, supervisors, clinical directors, educators, and those in similar roles were all doing this in tandem with managing their own personal and professional challenges around the pandemic.

Telemental health was already a modality that some practitioners opted to use pre-pandemic with studies attesting to its usefulness and efficacy (Andersson et al., 2019; Titov et al., 2018; Webb et al., 2017). The introduction of high-speed Internet and greater access to laptops and smartphones has made telehealth increasingly feasible (Sammons et al., 2020). Still, telehealth coverage before the pandemic was minimal and limited, with a complex regulatory framework, more of a niche healthcare delivery model in part due to the absence of uniform coverage from insurance providers or between states as well as adoption/implementation barriers like high startup costs, shifts in workflow, practitioner buyin, and patient interest (Weigel et al., 2020).

In March of 2020, soon after the federal government declared a public health emergency, Medicare and Medicaid coverage of telehealth was expanded allowing for full telehealth services and reducing or eliminating patient deductibles and co-pays (Inserro, 2020). COVID-19 spurred greater interest in telemedicine as policymakers, insurers, and care providers sought out ways to deliver services with limited risk of virus transmission (Weigel et al., 2020; Weineland et al., 2020). The federal government was instrumental in expanding coverage by allowing Medicare beneficiaries from any geographic location to access services from their homes, waiving HIPAA enforcement for telemedicine, and even relaxing requirements on the prescription of controlled substances (Weigel et al., 2020). The state governments also had a role in expanding telehealth access and coverage by relaxing many of the provider licensing requirements, supervision requirements, and written consents, with some states even mandating telehealth reimbursement for fully insured private plans (Weigel et al., 2020,).

Other private insurance providers followed in step initiating similar changes (America's Health Insurance Providers [AHIP], 2021). The pandemic accelerated the use of 
telemental health making it significantly more ubiquitous as insurance companies followed Medicare/Medicaid in adjusting behavioral health services and expanding coverage of telehealth beyond traditional parameters to meet the increased need and limited access to faceto-face services (Blue Cross Blue Shield, 2020). Taken together, these changes had significant implications for mental health services including who needed services, how services were delivered, where services were delivered, and how service providers were mobilized to meet the needs of a growing client population.

\section{Private Practice Shifts}

Due to the risk of infection transmission from face-to-face psychotherapeutic care, telehealth was the most recommended solution to offer clients continuation of care and access to care providers for those seeking to initiate services (Humer et al., 2020; Markowitz et al., 2020; Sampaio et al., 2021). The rapid shift to telehealth has been described as amounting to 10 years of change taking place over one week (Mueller, 2020). Sammons et al. (2020) noted that prior to the pandemic, only $29 \%$ of providers were using online platforms for a portion of their practice to current estimates of over $80 \%$ of providers practicing almost exclusively via telehealth. Barney et al. (2020) also noted a dramatic surge in telehealth visits at their Adolescent and Young Adult Medicine Clinic, increasing from zero to $97 \%$ of patient meetings in a single month. In fact, researchers contended that COVID-19 presented a turning point for the adoption of telemental health, offering a greater catalyst for the rapid implementation of telehealth than decades of research promoting the efficacy and economics of telehealth (Mohr et al., 2018; Pierce et al., 2021; Wind et al., 2020).

While telehealth can include various media platforms and phone systems, videoconferencing (e.g., Zoom, Doxy.me) was the most widely utilized medium (FernándezÁlvarez \& Fernández-Álvarez, 2021; Smoktunowicz et al., 2020). Changes in insurance coverage of telehealth opened the door to service continuity but presented challenges to therapists who were less comfortable with the technology associated with telehealth. Cataldo et al. (2021) acknowledged that for clinicians with a long history of face-toface talk therapy, shifting sessions was not a simple task. Additionally, with the relationship being a significant factor in positive therapeutic outcomes (Rogers, 1979), psychotherapists maintained reservations that telemental health would impact the rapport-building process and capacity (Cataldo et al., 2021). Boldrini et al. (2020) found that psychotherapist satisfaction with telehealth was influenced by the rate of interrupted treatments, their previous experience with telehealth, their beliefs about telehealth with their specific theoretical orientation, and the use of video conferencing over telephone-delivered services.

Despite therapist concern about telehealth and its efficacy, a mounting body of evidence suggests that telehealth offers comparable results to in-person psychotherapy (Lopez et al., 2019; Norwood et al., 2018; Simpson \& Reid, 2014). Simpson and Reid (2014) assert that the therapeutic alliance, a critical part of the therapeutic process, can be fostered in psychotherapy via videoconference, as clients rated connection and presence at least equally as strongly as face-to-face services across a number of different diagnostic groups. Norwood et al. (2018) asserted that while there was some indication that the therapeutic alliance was not as strong in telehealth, that target symptom reduction was equivalent. Lopez et al. (2019) found that practitioners generally have more reservations about the limitations of telehealth than patients do.

Psychotherapists also worried about telehealth in relation to HIPAA, security and confidentiality, technical logistics and failures, regulatory and legal changes, and managing insurance and reimbursement (FernándezÁlvarez \& Fernández-Álvarez, 2021). As Markowitz et al. (2020) explained, telehealth presented some major technical hurdles like challenges connecting, frozen screens, delayed audio, dropped calls, and more, all adding to therapist attitudes about telehealth and its efficacy. Thompson-de Benoit and Kramer (2020) noted that good connectivity, a good microphone, adequate lighting, a camera at eye level to enhance eye contact, and limiting distractions like notifications and email were critical to successful teletherapy. 
Furthermore, some psychotherapists expressed fear of managing high-need patients via telehealth (Cataldo et al., 2021; Cullen et al., 2020). For example, suicide risk is often higher during a disaster or global threat like COVID-19, and this paired with a lack of face-to-face contact can lead practitioners to feel like they are inadequately prepared to manage risk (Gunnell et al., 2020). Additionally, some diagnoses like severe eating disorders are managed with regular weighing and other interventions that are not as easily delivered remote without thoughtful and creative adjustments (Matheson et al., 2020). Still, there is mounting evidence that many serious disorders like obsessive-compulsive disorder, bipolar disorders, suicide ideation, psychosis, and post-traumatic stress disorder are treatable via telehealth (Aafjes-van Doorn et al., 2020; DeLuca et al., 2020; De Siqueira et al., 2020; Hasson-Ohayon \& Lysaker, 2020; Mcginn et al., 2019).

While therapists reported appreciating elements of telehealth, like a reduced commute, they also missed the transitional buffer that working outside of their home provided them and reported greater fatigue and physical discomfort with telehealth (Markowitz et al., 2020). At times, telehealth could offer a window into a client's life that could not be seen via traditional office visits; however, some therapists reported this as distracting or disruptive as client behavior, pets, children, and family complicated sessions (Gabbard, 2021). Additionally, video conferencing seemed to require greater attention and focus than face-to-face sessions, as there is more difficulty in processing nonverbal cues leading to additional therapist fatigue (Gabbard, 2021).

\section{Private Practice Careers}

While private practice therapists make up a substantial percentage of mental health providers, there is a dearth of literature specific to this population. Harrington (2013) reviewed a decade of noted journals related to major licenses in the field of psychotherapy, which included the American Psychological Association (APA), the National Association of Social Workers (NASW), and The Journal of Marital \& Family Therapy and found that no special issues centered entirely on private practice and a scant number of articles specific to private practice. A review of the more current available research reveals limited progress in this area. While there are some estimations of the various numbers of behavioral health practitioners, there is almost no information on how many psychotherapists are in private practice, and it was found that most state licensing boards do not maintain easily accessible data about how many licensed or pre-licensed therapists work in private practice (Harrington, 2013). Given the extent to which mental health services are provided in outpatient settings, it is surprising that this data is not further studied and that the decisions leading up to and experiences of maintaining a private practice are incredibly underexplored. Even less is known about practitioners who pursued private practice during the global pandemic. The aim of this research is to address these gaps in the literature.

\section{Discussion}

Many psychotherapists will go into private practice during the course of their careers as an independent practice may offer autonomy, professional growth, scheduling and workload flexibility, relief from burnout in previous employment, and higher compensation. Unfortunately, very little is known about how many clinicians identify as private practitioners and why they choose that role for their work (Harrington, 2013). While private practice can be enticing, there are barriers to establishing a private psychotherapy practice, including startup costs, commercial office leasing, the complexities of insurance and managed care, the absence of benefits like healthcare, and the perceived isolation and lack of support (Harrington, 2013). COVID-19 led to widespread adoption of telehealth and resulted in shifting attitudes regarding the implementation and efficacy of telehealth (Békés \& Aafjes-van Doorn, 2020). Given that a large percentage of psychotherapeutic services are provided in private practice settings and therapists support clients through a variety of micro and macro level issues and crises, it is important to understand career motivations, barriers and benefits of independent practice, treatment 
approaches and outcomes, and the experiences of the providers.

Future research could explore the experiences of private practice therapists during the COVID-19 pandemic. This may provide insight on motivations to start or sustain independent practice and the impact of supporting clients during a pandemic. Additionally, a quantitative design could explore the relationship between variables such as competency, treatment approach, time in practice, and geography and treatment outcomes. Finally, educational programs preparing clinicians to enter the workforce can expand their focus on work preparedness and treatment populations to better encompass the nuances of private practice and pandemic counseling as both separate and overlapping phenomena.

\section{References}

Aafjes-van Doorn, K., Békés, V., \& Prout, T. A. (2020). Grappling with our therapeutic relationship and professional self-doubt during COVID-19: Will we use video therapy again? Counselling Psychology Quarterly. https://doi.org/10.1080/09515070.202 $\underline{0.1773404}$

Aafjes-van Doorn, K., Békés, V., Prout, T. A., \& Hoffman, L. (2020). Psychotherapists' vicarious traumatization during the COVID-19 pandemic. Psychological Trauma: Theory, Research, Practice \& Policy, 12, S148-S150. https://doi.org/10.1037/tra0000868

Abbott, A. (2021, February 3). COVID's mentalhealth toll: How scientists are tracking a surge in depression. Nature.

https://www.nature.com/articles/d41586-021$\underline{00175-z}$

Ahorsu, D. K., Lin, C. Y., Imani, V., Saffari, M., Griffiths, M. D., \& Pakpour, A. H. (2020). The fear of COVID-19 scale: Development and initial validation. International Journal of Mental Health and Addiction, 1-9. https://doi.org/10.1007/s11469-020-00270-8

AJMC. (2021, January 21). A Timeline of COVID-19 Developments in 2020. American Journal of Managed Care. https://www.ajmc.com/view/a-timeline-ofcovid19-developments-in-2020

America's Health Insurance Providers [AHIP]. (2021, April 8). Health insurance providers respond to Coronavirus (COVID-19).

https://www.ahip.org/health-insurance-providersrespond-to-coronavirus-covid-19/

Anderson, M. L., Goodman, J., \& Schlossberg, N. K. (2012). Counseling adults in transition: Linking Schlossberg's theory with practice in a diverse world (4th ed.). Springer Publishing Company.

Andersson, G., Carlbring, P., Titov, N., \& Lindefors, N. (2019). Internet interventions for adults with anxiety and mood disorders: A narrative umbrella review of recent metaanalyses. The Canadian Journal of Psychiatry, 64(7), 465-

470. https://doi.org/10.1177/0706743719839381

Anzaldua, A., \& Halpern, J. (2021). Can clinical empathy survive? Distress, burnout, and malignant duty in the age of COVID-19. The Hastings Center Report, 51(1), 22-27. https://doi.org/10.1002/hast.1216

Barney, A., Buckelew, S., Mesheriakova, V., \& Raymond-Flesch, M. (2020). The COVID-19 pandemic and rapid implementation of adolescent and young adult telemedicine: Challenges and opportunities for innovation. The Journal of Adolescent Health: Official Publication of the Society for Adolescent Medicine, 67(2), 164-171. https://doi.org/10.1016/j.jadohealth.2020.05.006

Barrett, A., Kajamaa, A., \& Johnston, J. (2020). How to ... be reflexive when conducting qualitative research. Clinical Teacher, 17(1), 912. https://doi.org/10.1111/tct.13133

Békés, V., \& Aafjes-van Doorn, K. A. (2020). Psychotherapists' attitudes toward online therapy during the COVID-19 pandemic. Journal of Psychotherapy Integration, 30(2), 238-247. https://doi.org/10.1037/int0000214

Bentall, R. (2020). COVID-19 psychological research consortium. Initial findings on COVID19 and mental health in the UK. https://drive.google.com/file/d/1A95KvikwK32ZA X387nGPNBCnoFktdumm/view 
Blue Cross Blue Shield (BCBS). (2020, May 11). $75 \%$ of Americans with behavioral health conditions are continuing therapy services during the ongoing COVID-19 pandemic. https://www.bcbs.com/press-releases/75percent-of-americans-behavioral-healthconditions-are-continuing-therapy-servicesduring-covid19-pandemic

Boden, M., Zimmerman, L., Azevedo, K. J., Ruzek, J. I., Gala, S., Abdel Magid, H. S., Cohen, N., Walser, R., Mahtani, N. D., Hoggatt, K. J., \& McLean, C. P. (2021). Addressing the mental health impact of COVID-19 through population health. Clinical Psychology Review, 85, 102006. https://doi.org/10.1016/j.cpr.2021.102006

Boldrini, T., Schiano Lomoriello, A., Del Corno, F., Lingiardi, V., \& Salcuni, S. (2020). Psychotherapy during COVID-19: How the clinical practice of Italian psychotherapists changed during the pandemic. Frontiers in Psychology, 11, 591170.

https://doi.org/10.3389/fpsyg.2020.591170

Brooks, S. K., Webster, R. K., Smith, L. E., Woodland, L., Wessely, S., Greenberg, N., \& Rubin, G. (2020). The psychological impact of quarantine and how to reduce it: Rapid review of the evidence. Lancet, 395, 912-920.

https://doi.org/10.1016/S0140-6736(20)30460-8

Cataldo, F., Chang, S., Mendoza, A., \& Buchanan, G. (2021). A perspective on clientpsychologist relationships in videoconferencing psychotherapy: Literature review. JMIR Mental Health, 8(2), e19004.

http://dx.doi.org/10.2196/19004

Centers for Disease Control and Prevention. (2020). First travel-related case of 2019 novel Coronavirus detected in United States. U.S. Department of Health and Human Services. https://www.cdc.gov/media/releases/2020/p0121 -novel-coronavirus-travel-case.html

Centers for Disease Control and Prevention. (2021, May 24). Basics of COVID-19. U.S. Department of Health and Human Services. https://www.cdc.gov/coronavirus/2019ncov/your-health/about-covid-19/basics-covid19.html\#: :text=On\%20February\%2011\%2C\%2 02020,sticking\%20out\%20of\%20them
Charmaz, K. C. (2006). Constructing grounded theory: A practical guide through qualitative analysis. Thousand Oaks, CA: Sage.

Cipolletta, S., \& Ortu, M. (2020). COVID-19: Common constructions of the pandemic and their implications. Journal of Constructivist Psychology, 34(3), 278-294. https://doi.org/10.1080/10720537.2020.1818653

Cullen, W., Gulati, G., \& Kelly, B. D. (2020). Mental health in the COVID-19 pandemic. QJM: Monthly Journal of the Association of Physicians, 113(5), 311-312. https://doi.org/10.1093/qjmed/hcaa110

Czeisler, M. É., Lane, R. I., Petrosky, E., Wiley, J. F., Christensen, A., Njai, R., Weaver, M. D., Robbins, R., Facer-Childs, E. R., Barger, L. K., Czeisler, C. A., Howard, M. E., Shantha, M. W., \& Rajaratnam, S. M. W. (2020). Mental health, substance use, and suicidal ideation during the COVID-19 pandemic - United States June 2430 2020. MMWR Morb Mortal Weekly Report, 69(32), 1049-1057.

https://doi.org/10.15585/mmwr.mm7932a1

Davis, M. L., Witcraft, S. M., Baird, S. O., \& Smits, J. A. J. (2017). Learning principles in CBT. In S. G. Hofmann \& G. J. G. Asmundson (Eds.), The science of cognitive behavioral therapy (pp. 51-76). Elsevier Academic Press. https://doi.org/10.1016/B978-0-12803457-6.00003-9

Davulis, T., Gasparènienè, L., \& Raistenskis, E. (2021). Assessment of the situation concerning psychological support to the public and business in the extreme conditions: Case of COVID19. Entrepreneurship and Sustainability Issues, 8(3), 308-323. http://dx.doi.org/10.9770/jesi.2021.8.3(19)

DeLuca, J. S., Andorko, N. D., Chibani, D., Jay, S. Y., Rakhshan Rouhakhtar, P. J., Petti, E., Klaunig, M. J., Thompson, E. C., Millman, Z. B., Connors, K. M., Akouri-Shan, L., Fitzgerald, J., Redman, S. L., Roemer, C., Bridgwater, M. A., DeVylder, J. E., King, C. A., Pitts, S. C., Reinblatt, S. P., ... Schiffman, J. (2020). Telepsychotherapy with youth at clinical high risk for psychosis: clinical issues and best practices during the COVID-19 pandemic. $J$. Psychother. Integr., 30, 304-331. https://doi.org/10.1037/int0000211 
De Siqueira, L., Camila, R., Silva, R., Beny, D., \& Khafif, T. C. (2020). Psychological therapies and psychoeducational recommendations for bipolar disorder treatment during COVID-19 pandemic. Bipolar Disorder, 22, 644-646. https://doi.org/10.1111/bdi.12981

Duan, L., \& Zhu, G. (2020). Psychological interventions for people affected by the COVID19 epidemic. Lancet Psychiatry, 7(4), 300-302. https://doi.org/10.1016/S2215-0366(20)30073-0

Ettman, C. K., Abdalla, S. M., Cohen, G. H., Sampson, L., Vivier, P. M., \& Galea, S. (2020). Prevalence of depression symptoms in US adults before and during the COVID-19 pandemic. JAMA network open, 3(9), e2019686. https://doi.org/10.1001/jamanetworkopen.2020.1 $\underline{9686}$

Fernández-Álvarez, J., \& Fernández-Álvarez, H. (2021). Videoconferencing psychotherapy during the pandemic: Exceptional times with enduring effects? Frontiers In Psychology, 12, 589536. https://doi.org/10.3389/fpsyg.2021.589536

Finlay, L. (1998). Reflexivity: An essential component for all research? British Journal of Occupational Therapy, 61(10), 453456. https://doi.org/10.1177/0308022698061010 $\underline{05}$

Gabbard, G. (2021). Expert opinion in psychotherapy: The transformation of psychotherapy practice in the Covid-19 era. Personalized Medicine in Psychiatry, 27, 10075. https://doi.org/10.1016/j.pmip.2021.100075

Gibson, B., Schneider, J., Talamonti, D., \& Forshaw, M. (2021). The impact of inequality on mental health outcomes during the COVID-19 pandemic: A systematic review. Canadian Psychology, 62(1), 101-126. http://dx.doi.org/10.1037/cap0000272

Giorgi, G., Lecca, L. I., Alessio, F., Finstad, G. L., Bondanini, G., Lulli, L. G., Arcangeli, G., \& Mucci, N. (2020). COVID-19 related mental health effects in the workplace: A narrative review. International Journal of Environmental Research and Public Health, 17(21), 7857. https://doi.org/10.3390/ijerph17217857

Gordon, J. (2021, April 9). One year in: COVID19 and mental health. National Institute of
Mental Health.

https://www.nimh.nih.gov/about/director/messag es/2021/one-year-in-covid-19-and-mental-health

Gunnell, D., Appleby, L., Arensman, E., Hawton, K., John, A., Kapur, N., Khan, M., O'Connor, R. C., \& Pirkis, J., \& COVID-19 Suicide Prevention Research Collaboration (2020). Suicide risk and prevention during the COVID-19 pandemic. The Lancet Psychiatry, 7(6), 468-471.

https://doi.org/10.1016/S2215-0366(20)30171-1

Harrington, J. A. (2013). Contemporary issues in private practice: Spotlight on the self-employed mental health counselor. Journal of Mental Health Counseling, 35(3), 189-197. https://doi.org/10.17744/mehc.35.3.8742717176 $\underline{154187}$

Hasson-Ohayon, I., \& Lysaker, P. H. (2020). Special challenges in psychotherapy continuation and adaption for persons with schizophrenia in the age of coronavirus (COVID19). Counseling Psychology Quarterly, 1-9. https://doi.org/10.1080/09515070. $\underline{2020.1781595}$

Hays, D. G., \& Wood, C. (2011). Infusing qualitative traditions in counseling research designs. Journal of Counseling \& Development, 89, 288-295. https://doi.org/10.1002//.15 566678.2011.tb00091.x

Holingue, C., Kalb, L. G., Riehm, K. E., Bennett, D., Kapteyn, A., Veldhuis, C. B., Johnson, R. M., Fallin, M. D., Kreuter, F., Stuart, E. A., \& Thrul, J. (2020). Mental distress in the United States at the beginning of the COVID-19

pandemic. American Journal of Public

Health, 110(11), 1628-1634.

https://doi.org/10.2105/AJPH.2020.305857

Holland, K. M., Jones, C., Vivolo-Kantor, A. M., Idaikkadar, N., Zwald, M., Hoots, B., Yard, E., D'Inverno, A., Swedo, E., Chen, M. S., Petrosky, E., Board, A., Martinez, P., Stone, D. M., Law, R., Coletta, M. A., Adjemian, J., Thomas, C., Puddy, R. W., Peacock, G., ... Houry, D. (2021). Trends in US emergency department visits for mental health, overdose, and violence outcomes before and during the COVID-19 pandemic.

JAMA Psychiatry, 78(4), 372-379.

https://doi.org/10.1001/jamapsychiatry.2020.440 $\underline{2}$ 
Holmes, E. A., O'Connor, R. C., Perry, V. H., Tracey, I., Wessely, S., Arseneault, L., Ballard, C., Christensen, H., Cohen Silver, R., Everall, I., Ford, T., John, A., Kabir, T., King, K., Madan, I., Michie, S., Przybylski, A. K., Shafran, R., Sweeney, A., Worthman, C. M., ... Bullmore, E. (2020). Multidisciplinary research priorities for the COVID-19 pandemic: A call for action for mental health science. The Lancet Psychiatry, 7(6), 547-560. https://doi.org/10.1016/S22150366(20)30168-1

Hopkins, J. S., \& Russell, D. (2020, April 2). The mental health effects of coronavirus are a "slowmotion disaster". Mother Jones.

https://www.motherjones.com/ coronavirusupdates/2020/04/the-mental-health-effects-ofcoronavirus-are-a-slow-motion-disaster/

Humer, E., Stippl, P., Pieh, C., Pryss, R., \& Probst, T. (2020). Experiences of psychotherapists with remote psychotherapy during the COVID-19 pandemic: Cross-sectional web-based survey study. Journal of Medical Internet Research, 22(11), e20246.

https://doi.org/10.2196/20246

Humer, E., Stippl, P., Pieh, C., Schimböck, W., \& Probst, T. (2020). Psychotherapy via the Internet: What programs do psychotherapists use, how well-informed do they feel, and what are their wishes for continuous education? International Journal of Environmental Research and Public Health, 17(21), 81-82.

https://doi.org/10.3390/ijerph17218182

Inserro, A. (2020, March 17). CMS unveils temporary change allowing wider use of telehealth during COVID-19 pandemic. American Journal of Managed Care. https://www.ajmc.com/view/cms-unveilstemporary-change-allowing-wider-use-oftelehealth-during-covid19-pandemic

Itrat, A., Jagadheesan, K., Danivas, V., \& Lakra, V. (2020). A comparative study of access to inpatient psychiatric treatment in a public mental health service in Melbourne during COVID19. Indian Journal of Psychiatry, 62(3), S454S458.

https://doi.org/10.4103/psychiatry.IndianJPsychi atry 85220
Javakhishvili, J. D., Ardino, V., Bragesjö, M., Kazlauskas, E., Olff, M., \& Schäfer, I. (2020). Trauma-informed responses in addressing public mental health consequences of the COVID-19 pandemic: Position paper of the European society for traumatic stress studies (ESTSS). European Journal of Psychotraumatology, 11(1), 1780782. http://dx.doi.org/10.1080/20008198.2020.17807 $\underline{82}$

Javed, B., Sarwer, A., Soto, E. B., \& Mashwani, Z. U. (2020). The coronavirus (COVID-19) pandemic's impact on mental health. The International Journal of Health Planning and Management, 35(5), 993-996.

https://doi.org/10.1002/hpm.3008

Jordan, H. T., Osahan, S., Li, J., Stein, C. R., Friedman, S. M., Brackbill, R. M., Cone, J. E., Gwynn, C., Mok, H. K., \& Farfel, M. R. (2019). Persistent mental and physical health impact of exposure to the September 11, 2001 World Trade Center terrorist attacks. Environmental Health: A Global Access Science Source, 18(1), 1-16. https://doi.org/10.1186/s12940-019-0449-7 Joshi, G., \& Sharma, G. (2020). Burnout: A risk factor amongst mental health professionals during COVID-19. Asian Journal of Psychiatry, 54, 102-300.

https://doi.org/10.1016/j.ajp.2020.102300

Kaiser Family Foundation. (n.d.). Adults reporting unmet need for mental health treatment in the past year.

https://www.kff.org/other/state-indicator/adultsreporting-unmet-need-for-mental-healthtreatment-in-the-pastyear/?currentTimeframe $=0$ \&sortModel $=\% 7 \mathrm{~B} \% 22$ colld\%22:\%22Location\%22,\%22sort\%22:\%22as C\%22\%7D

Khan, K. S., Mamun, M. A., Griffiths, M. D., \& Ullah, I. (2020). The mental health impact of the COVID-19 pandemic across different cohorts. International Journal of Mental Health and Addiction, 1-7. https://doi.org/10.1007/s11469-020-00367-0

Lee, J. (2020). Mental health effects of school closures during COVID-19. The Lancet Child \& Adolescent Health, 4(6), 421. https://doi.org/10.1016/S2352-4642(20)30109-7 
Lewis, Y. D., Elran-Barak, R., Grundman-Shem Tov, R., \& Zubery, E. (2021). The abrupt transition from face-to-face to online treatment for eating disorders: A pilot examination of patients' perspectives during the COVID-19 lockdown. Journal of Eating Disorders, 9, 1-11. http://dx.doi.org/10.1186/s40337-021-00383-y

Li, W., Yang, Y., Liu, Z. H., Zhao, Y. J., Zhang, Q., Zhang, L., Cheung, T., \& Xiang, Y. T. (2020). Progression of mental health services during the COVID-19 outbreak in China. International Journal of Biological Sciences, 16(10), 17321738. https://doi.org/10.7150/ijbs. 45120

Litam, S. D., \& Hipolito-Delgado, C. (2021). When being "essential" illuminates disparities: Counseling clients affected by COVID-

19. Journal of Counseling and Development, 99, 3-10.

Lopez, A., Schwenk, S., Schneck, C. D., Griffin, R. J., \& Mishkind, M. C. (2019). Technologybased mental health treatment and the impact on the therapeutic alliance. Curr. Psychiatry Rep. 21, 1-7. https://doi.org/10.1007/ s11920$\underline{019-1055-7}$

Lu, W., Wang, H., Lin, Y., \& Li, L. (2020). Psychological status of medical workforce during the COVID-19 pandemic: A cross-sectional study. Psychiatry Research, 288, 112936. https://doi.org/10.1016/j.psychres.2020.112936

Markowitz, J. C., Milrod, B., Heckman, T. G., Bergman, M., \& Amsalem, D. (2020).

Psychotherapy at a distance. Am. J. Psychiatry, 1-7.

https://doi.org/10.1176/appi.ajp.2020.20050557

Matheson, B. E., Bohon, C., \& Lock, J. (2020). Family-based treatment via videoconference:

Clinical recommendations for treatment providers during COVID-19 and beyond. Int. J. Eat. Disord. 53, 1142-1154.

https://doi.org/10.1002/ eat.23326

Mauro, V., Lorenzo, M., Paolo, C., \& Sergio, H. (2020). Treat all COVID 19 positive patients, but do not forget those negative with chronic diseases. Internal and Emergency Medicine. https://doi.org/10.1007/s 11739-020-02395-z

McBeath, A. G., du Plock, S., \& BagerCharleson, S. (2020). The challenges and experiences of psychotherapists working remotely during the coronavirus pandemic. Counselling and Psychotherapy Research, 20(3), 394-405. https://doi.org/10.1002/capr.12326

Mcginn, M. M., Roussev, M. S., Shearer, E. M., Mccann, R. A., Rojas, S. M., \& Felker, B. L. (2019). Recommendations for using clinical video telehealth with patients at high risk for suicide. Psychiatr. Clin. North Am., 42, 587-595. https://doi.org/10.1016/i.psc.2019.08.009

McKinley, J. (2015). Critical argument and writer identity: Social constructivism as a theoretical framework for EFL academic writing. Critical Inquiry in Language Studies, 12(3), 184-

207. https://doi.org/10.1080/15427587.2015.106 0558

Mohr, D. C., Riper, H., \& Schueller, S. M. (2018). A solution-focused research approach to achieve an implementable revolution in digital mental health. JAMA psychiatry, 75(2), 113114.

https://doi.org/10.1001/jamapsychiatry.2017.383 $\underline{8}$

Moustakas, C. E. (1994). Phenomenological research methods. Sage Publications, Inc. Mueller, B. (2020, April 4). Telemedicine arrives in the U.K.: '10 years of change in one week'. The New York Times.

https://www.nytimes.com/2020/04/04/world/euro pe/telemedicine-uk-coronavirus.html

National Archives. (2020, March 13). Declaring a national emergency concerning the novel Coronavirus disease (COVID-19) outbreak. Executive Office of the President. https://www.federalregister.gov/documents/2020 103/18/2020-05794/declaring-a-nationalemergency-concerning-the-novel-coronavirusdisease-covid-19-outbreak

National Institute of Mental Health. (n.d.). What is telemental health? U.S. Department of Health and Human Services.

https://www.nimh.nih.gov/health/publications/wh at-is-telemental-health/

Nimmon, L., Paradis, E., Schrewe, B., \& Mylopoulos, M. (2016). Integrating theory into qualitative medical education research. Journal of Graduate Medical Education, 8(3), 437-438. https://doi.org/10.4300/JGME-D-16-00206.1 
Norwood, C., Moghaddam, N. G., Malins, S., \& Sabin-Farrell, R. (2018). Working alliance and outcome effectiveness in videoconferencing psychotherapy: A systematic review and noninferiority meta-analysis. Clin. Psychol. Psychother., 25, 797-808.

https://doi.org/110.1002/cpp.2315

Otu, A., Carlo, H. C., \& Yaya, S. (2020). Mental health and psychosocial well-being during the COVID-19 pandemic: The invisible elephant in the room. International Journal of Mental Health Systems, 14, 1-5.

http://dx.doi.org/10.1186/s13033-020-00371-w

Palinkas, L. A., Horwitz, S. M., Green, C. A., Wisdom, J. P., Duan, N., \& Hoagwood, K. (2015). Purposeful sampling for qualitative data collection and analysis in mixed method implementation research. Administration and Policy in Mental Health, 42(5), 533-544. https://doi.org/10.1007/s10488-013-0528-y

Panchal, N., Kamal, R., Cox, C., \& Garfield, R. (2021, February 10). The implications of COVID19 for mental health and substance use. Kaiser Family Foundation.

https://www.kff.org/coronavirus-covid-19/issuebrief/the-implications-of-covid-19-for-mentalhealth-and-substance-use/

Patrick, S. L., \& Cormier, H. C. (2020). Are our lives the experiment? COVID-19 lessons during a chaotic natural experiment - $A$ commentary. Health Behavior \& Policy Review, 7(2), 165-169.

https://doi.org/10.14485/HBPR.7.2.10

Patton, M. Q. (2002). Qualitative research \& evaluation methods (3rd ed.). Sage.

Pfefferbaum, B., \& North, C. S. (2020). Mental health and the Covid-19 pandemic. N. Engl. J. Med., 383, 510-512.

https://doi.org/10.1056/NEJMp2008017

Pierce, B. S., Perrin, P. B., Tyler, C. M., McKee, G. B., \& Watson, J. D. (2021). The COVID-19 telepsychology revolution: A national study of pandemic-based changes in U.S. mental health care delivery. The American Psychologist, 76(1), 14-25. https://doi.org/10.1037/amp0000722

Polovoy, C., \& Kornak, J. (2020). COVID-19: Private practitioners report on office closures and telepractice. Leader Live. https://leader.pubs.asha.org/do/10.1044/covid19-private-practitioners-report-on-closures-andtelepractice/full/?utm source=TrendMD\&utm $\mathrm{m}$ edium=cpc\&utm campaign=The ASHA Leader TrendMD 0

Prime, H., Wade, M., \& Browne, D. T. (2020). Risk and resilience in family well-being during the COVID-19 pandemic. The American

Psychologist, 75(5), 631-643.

https://doi.org/10.1037/amp0000660

Punia, V., Nasr, G., Zagorski, V., Lawrence, G., Fesler, J., Nair, D., \& Najm, I. (2020). Evidence of a rapid shift in outpatient practice during the COVID-19 pandemic using telemedicine. Telemedicine Journal and Ehealth: The Official Journal of the American Telemedicine Association, 26(10), 1301-1303. https://doi.org/10.1089/tmj.2020.0150

Rehm, J., Kilian, C., Ferreira-Borges, C., Jernigan, D., Monteiro, M., Parry, C. D. H., Sanchez, Z., \& Manthey, J. (2020). Alcohol use in times of the COVID 19: Implications for monitoring and policy. Drug Alcohol Review, 39, 301-304. https://doi.org/10.1111/dar.13074

Rogers, C. R. (1979). The foundations of the person-centered approach. Education, 100(2), 98-107.

Rokach, A., \& Boulazreg, S. (2020). The COVID-19 era: How therapists can diminish burnout symptoms through self-care. Current Psychology, 1-18. https://doi.org/10.1007/s12144-020-01149-6

Rothe, J., Buse, J., Uhlmann, A., Bluschke, A., \& Roessner, V. (2021). Changes in emotions and worries during the Covid-19 pandemic: An online-survey with children and adults with and without mental health conditions. Child and Adolescent Psychiatry and Mental Health, 15(1), 1-9. https://doi.org/10.1186/s13034-021-00363-9

Salvagioni, D., Melanda, F. N., Mesas, A. E., González, A. D., Gabani, F. L., \& Andrade, S. M. (2017). Physical, psychological and occupational consequences of job burnout: A systematic review of prospective studies. PloS One, 12(10), e0185781.

https://doi.org/10.1371/journal.pone.0185781

Sammons, M. T., VandenBos, G. R., \& Martin, J. N. (2020). Psychological practice and the 
COVID-19 crisis: A rapid response survey. Journal of Health Service Psychology, 1-7. https://doi.org/10.1007/s42843-020-00013$\underline{2}$

Sampaio, M., Haro, M., De Sousa, B., Melo, W. V., \& Hoffman, H. G. (2021). Therapists make the switch to telepsychology to safely continue treating their patients during the COVID-19 pandemic. Virtual reality telepsychology may be next. Frontiers In Virtual Reality, 1, 576421. https://doi.org/10.3389/frvir.2020.57642 1

Sher, L. (2020). The impact of the COVID-19 pandemic on suicide rates. QJM: Monthly Journal of the Association of Physicians, 113(10), 707-712. https://doi.org/10.1093/qjmed/hcaa202 Simon, N. M., Saxe, G. N., \& Marmar, C. R. (2020). Mental health disorders related to COVID-19-related deaths. JAMA, 324(15), 1493-1494.

https://doi.org/10.1001/jama.2020.19632

Simpson, S., Richardson, L., Pietrabissa, G., Castelnuovo, G., \& Reid, C. (2021). Videotherapy and therapeutic alliance in the age of COVID-19. Clinical Psychology \&

Psychotherapy, 28(2), 409-421.

https://doi.org/10.1002/cpp.2521

Simpson, S. G., \& Reid, C. L. (2014).

Therapeutic alliance in videoconferencing psychotherapy: A review. The Australian Journal of Rural Health, 22(6), 280-299.

https://doi.org/10.1111/ajr.12149

Smoktunowicz, E., Barak, A., Andersson, G., Banos, R. M., Berger, T., Botella, C., Dear, B. F., Donker, T., Ebert, D. D., Hadjistavropoulos, H., Hodgins, D. C., Kaldo, V., Mohr, D. C., Nordgreen, T., Powers, M. B., Riper, H., Ritterband, L. M., Rozental, A., Schueller, S. M., Titov, N., ... Carlbring, P. (2020). Consensus statement on the problem of terminology in psychological interventions using the Internet or digital components. Internet Interventions, 21, 100-331.

https://doi.org/10.1016/j.invent.2020.100331

Soklaridis, S., Lin, E., Lalani, Y., Rodak, T., \& Sockalingam, S. (2020). Mental health interventions and supports during COVID- 19 and other medical pandemics: A rapid systematic review of the evidence. General Hospital Psychiatry, 66, 133-146.

https://doi.org/10.1016/i.genhosppsych.2020.08. $\underline{007}$

Stewart, R. W., Orengo-

Aguayo, R., Young, J., Wallace, M.

W., Cohen, J. A., Mannarino, A. P., \& de

Arellano, M. A. (2020). Feasibility and effectiveness of a telehealth service delivery model for treating childhood post-traumatic stress: A community-based, open pilot trial of trauma-focused cognitive behavioral therapy. Journal of Psychotherapy Integration, 30, 274-

289. https://doi.org/10.1037/int0000225

Swartz, H. A. (2020). The role of psychotherapy during the COVID-19 pandemic. American Journal of Psychotherapy, 73(2), 41-42. https://doi.org/10.1176/appi.psychotherapy.2020 $\underline{0015}$

Szasz, G. (2020, June 16). The origin of pandemic-related words. The British Columbia Medical Journal (BCMJ).

https://bcmj.org/blog/origin-pandemic-relatedwords

Taquet, M., Luciano, S., Geddes, J. R., \& Harrison, P. J. (2021). Bidirectional associations between COVID-19 and psychiatric disorder: Retrospective cohort studies of 62,354 COVID19 cases in the USA. The Lancet Psychiatry, 8(2), 130-140. https://doi.org/10.1016/s2215-0366(20)30462-4

Taylor, S., Landry, C. A., Paluszek, M. M., Fergus, T. A., McKay, D., \& Asmundson, G. (2020). COVID stress syndrome: Concept, structure, and correlates. Depression and Anxiety, 37(8), 706-714.

https://doi.org/10.1002/da.23071

Thompson-de Benoit, A., \& Kramer, U. (2020). Work with emotions in remote psychotherapy in the time of Covid-19: A clinical experience.

Couns. Psychol. Q., 1-9.

https://doi.org/10.1080/09515070.2020.1770696

Tingbo, L. (2020). Handbook of COVID-19 prevention and treatment. The first affiliated hospital Zhejiang University School of Medicine. https://gmcc.alibabadoctor.com/preventionmanual/reader?pdf=Handbook\%20of\%20COVID 
19\%20Prevention\%20and\%20Treatment\%20(St andard).pdf\&opt=read\&version=standard\&langu age=en\&content $\mathrm{id}=$

Titov, N., Dear, B., Nielssen, O., Staples, L., Hadjistavropoulos, H., Nugent, M., Adlam, K., Nordgreen, T., Bruvik, K. H., Hovland, A., Repål, A., Mathiasen, K., Kraepelien, M., Blom, K., Svanborg, C., Lindefors, N., \& Kaldo, V. (2018). ICBT in routine care: A descriptive analysis of successful clinics in five countries. Internet Interventions, 13, 108-115.

https://doi.org/10.1016/j.invent.2018.07.006

U.S. Department of Health and Human Services. (n.d.). What is telehealth? How is telehealth different from telemedicine?

https://www.healthit.gov/faq/what-telehealthhow-telehealth-different-telemedicine

U.S. Department of Health and Human Services. (2016). Health resources and services administration/national center for health workforce analysis; substance abuse and mental health services administration/office of policy, planning, and innovation. National Projections of Supply and Demand for Behavioral Health Practitioners: 2013-2025.

https://bhw.hrsa.gov/sites/default/files/bureauhealth-workforce/data-research/behavioralhealth-2013-2025.pdf

van der Miesen, A. I. R., Raaijmakers, D., \& van de Grift, T. C. (2020). "You have to wait a little longer": Transgender (mental) health al risk as a consequence of deferring gender-affirming treatments during COVID-19, Archives of Sexual Behavior, 49(5), 1395-1399.

https://doi.org/10.1007/ si 0508-020-01754-3

Varker, T., Brand, R. M., Ward, J., Terhaag, S., \& Phelps, A. (2019). Efficacy of synchronous telepsychology interventions for people with anxiety, depression, post-traumatic stress disorder, and adjustment disorder: A rapid evidence assessment. Psychological Services, 16(4), 621-635.

Varpio, L., Paradis, E., Uijtdehaage, S., \& Young, M. (2020). The distinctions between theory, theoretical framework, and conceptual framework. Academic Medicine: Journal of the Association of American Medical Colleges, 95(7), 989-994.
https://doi.org/10.1097/ACM.000000000000307 $\underline{5}$

Vianna, E., \& Stetsenko, A. (2006). Embracing history through transforming it: Contrasting Piagetian versus Vygotskian (activity) theories of learning and development to expand constructivism within a dialectical view of history. Theory \& Psychology, 16(1), 81108. https://doi.org/10.1177/0959354306060108

Vindegaard, N., \& Benros, M. E. (2020). COVID19 pandemic and mental health consequences: Systematic review of the current evidence. Brain, Behavior, and Immunity, 89, 531-542.

https://doi.org/10.1016/j.bbi.2020.05.048

Wade, B. (2020). Psychotherapy in the age of Coronavirus: A reflection on collective discomfort. Psychiatric Services, 71(6), 639640. https://doi.org/10.1176/appi.ps.71701

Wang, C., Pan, R., Wan, X., Tan, Y., Xu, L., Ho, C. S., \& Ho, R. C. (2020). Immediate psychological responses and associated factors during the initial stage of the 2019 coronavirus disease (COVID-19) epidemic among the general population in China. International Journal of Environmental Research and Public Health, 17, 1729. https://doi.org/10.3390/ijerph17051729

Webb, C. A., Rosso, I. M., \& Rauch, S. L. (2017). Internet-based cognitive-behavioral therapy for depression: Current progress and future directions. Harvard Review of

Psychiatry, 25(3), 114-122.

https://doi.org/10.1097/HRP.0000000000000139

Weigel, G., Ramaswamy, A., Sobel, L., Salganicoff, A., Cubanski, J., \& Freed, M. (2020, May 11). Opportunities and barriers for telemedicine in the U.S. during the COVID-19 emergency and beyond. Kaiser Family Foundation. https://www.kff.org/womens-healthpolicy/issue-brief/opportunities-and-barriers-fortelemedicine-in-the-u-s-during-the-covid-19emergency-and-beyond/

Weineland, S., Ribbegårdh, R., Kivi, M., Bygdell, A., Larsson, A., Vernmark, K., \& Lilja, J. L. (2020). Transitioning from face-to-face treatment to iCBT for youths in primary care - Therapists' attitudes and experiences. Internet 
Interventions, 22, 100356.

https://doi.org/10.1016/j.invent.2020.100356

Wilkinson, H., Whittington, R., Perry, L., \& Eames, C. (2017). Examining the relationship between burnout and empathy in healthcare professionals: A systematic review. Burnout Research, 6, 18-29.

https://doi.org/10.1016/i.burn.2017.06.003

Wind, T. R., Rijkeboer, M., Andersson, G., \& Riper, H. (2020). The COVID-19 pandemic: The "black swan" for mental health care and a turning point for e-health. Internet Interv., 20, 100-317.

https://doi.org/10.1016/j.invent.2020.100317
World Health Organization. (2020, March 11). WHO director-general's opening remarks at the media briefing on COVID-19 - 11 March 2020 [Press release].

https://www.who.int/director-

general/speeches/detail/who-director-general-sopening-remarks-at-the-media-briefing-on-covid19---11-march-2020

Wright, J. H., \& Caudill, R. (2020). Remote treatment delivery in response to the COVID-19 pandemic. Psychotherapy and

Psychosomatics, 89(3), 130-132. https://doi.org/10.1159/000507376 